\title{
A VIA CRUCIS FEMININA NO PLANETA MINAS: RESISTÊNCIA E ENFRENTAMENTO NA LITERATURA DE FERNANDO GABEIRA
}

\author{
Tânia Maria de Oliveira Gomes
}

\begin{abstract}
RESUMO
Este artigo tem como objeto de estudo o livro de Fernando Gabeira, Sinais de Vida no Planeta Minas, obra que se destaca pela literatura engajada e pelo antagonismo aos mecanismos de escamoteação social. Neste ensejo, o presente texto se vale de um referencial bibliográfico calcado na Análise do Discurso, linha propícia ao fornecimento dos subsídios teóricos necessários para o exame do corpus selecionado.
\end{abstract}

PALAVRAS-CHAVE: discurso; memória discursiva; contexto.

\section{O espólio femíneo no globo mineiro}

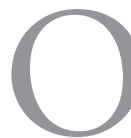

trabalho, que aqui se soleva, hasteia a flâmula dos ideais de liberdade e igualdade encontrados, a priori, no Estado Democrático de Direito, em que se encontra o Brasil. No entanto, apesar dessa alforria popular, que parece emergir em torno de tal estágio civil, faz-se necessário discutir acerca da outra face, por vezes nebulosa, que se oculta no maquinário social: a do autoritarismo. É, precisamente, a partir dessa temática que este artigo se ergue, tracejando, ao longo das laudas que o fundamentam, um repertório analítico-teórico calcado na interface entre a Análise do Discurso e a Literatura. Originário desta, o romance de Fernando Gabeira, Sinais de Vida no Planeta Minas, vislumbra-se como foco do exame acadêmico que se fundamenta naquela área, retratada por meio de teóricos como Charaudeau (2010), Marcuschi 
(2008), Brandão (2004) e Bakhtin (2003). No contexto literário gabeiriano, o autoritarismo parece se revelar nas dinâmicas sociais daqueles que se valem da dominação e da arbitrariedade como aparelhos regulatórios. Sob esse prisma, justifica-se a escolha da obra supracitada por esta apresentar o totalitarismo na sua máxima expressão, direcionado, sobretudo, às figuras femininas. Acerca da construção do livro nomeado, é o próprio Gabeira (1982) quem discorre, metalinguisticamente, sobre a ideia de tal narrativa:

Escrever sobre os pataxó [sic] era meu projeto de trabalho até a noite do réveillon. Eram quase duas horas quando tomei um barco do Arraial da Ajuda para Porto Seguro. [...] Sabe o que me ocorreu nesse barco, viajando no escuro, ouvindo música e com medo de afundar? Vou escrever um livro sobre as mulheres do Planeta onde nasci e passar o resto do dia dentro da água, pelo menos até o fim do ano (GABEIRA, 1982, p. 11-12).

Prosseguindo no seu devaneio sobre a temática do romance, o narrador-personagem elucida: "No bolso, trouxe quatro nomes de mulher: Tia Pantera, Beja, Chica da Silva e Olímpia de Ouro Preto. Não me pergunte por que quatro e não oito, pois não saberia responder" (GABEIRA, 1982, p. 13). A essas quatro personagens, somou-se uma quinta protagonista, assim incorporada ao enredo:

Nos meus primeiros dias de janeiro em Minas chovia muito. Vivia ensopado e consciente de que, em algum tempo remoto do universo, as pessoas se deixavam queimar na areia bocejando gostosamente, amolecidas pelo sol e pela água do mar. Tiburtina. Assim, armada de dois imaginários revólveres, ela entrou na minha pequena lista, descortinando um lugar que não suspeitava visitar no momento: o sertáo (GABEIRA, 1982, p. 14).

Delimitadas tais personalidades, o narrador dá início à sua trama, misto de ficção e jornalismo histórico, que refaz a trajetória feminina de cinco mulheres apartadas por largos eixos temporais, todos estes conduzidos pela dogmática religiosa. Nesse caminho, o legado deixado por cada uma daquelas figuras parece se tocar, assumindo um tom profético que teima em prenunciar 
um destino semelhante àquelas que descendem da mesma terra, do mesmo Planeta: Minas Gerais. Sobre esse locus, avultam-se memórias e discursos que denunciam o despotismo vivenciado naquela porção do globo terrestre, tão bem conhecida por Gabeira (1982). A respeito do autor, rosto subjacente à obra, torna-se imperioso retratar, ainda que en passant, o percurso vital inaugurado por ele "no interior de uma família mineira, em 17 de fevereiro de 1941, em Juiz de Fora”, caminho de vida que culminaria na solidificação de "um dos mais controversos e editorialmente mais bem sucedidos autor de memórias sobre a guerrilha urbana: Fernando de Paula Nagle Gabeira” (SILVA, 2006, p. 60). Acerca desse escritor mineiro, sabe-se que:

Gabeira iniciou sua carreira de jornalista ao fim dos anos 1950 em Juiz de Fora, onde também se tornou secretário da União Brasileira de Estudantes Secundaristas (UBES). Em 1960, muda-se para o Rio de Janeiro, após uma rápida passagem por Belo Horizonte, para trabalhar como redator do Jornal do Brasil, num período do dia, bem como subsecretário de oficina do semanário Panfleto, que defendia as posiçóes da ala à esquerda do PTB. Ainda no Jornal do Brasil, em 1964, passa a atuar no movimento sindical dos jornalistas. Numa dupla vida que, de um lado, lhe abria uma promissora carreira profissional, (sendo aos 23 anos pauteiro e mais tarde promovido a Chefe do Departamento de Pesquisas do mesmo jornal); e, por outro, buscando uma atuação num jornal clandestino de um partido político, Gabeira opta pelo segundo, iniciando militância e atividade clandestina na Dissidência da Guanabara do Partido Comunista (DI-GB ou a $O$., como aparece em seus livros), mais tarde, Movimento Revolucionário 8 de Outubro - MR8, em 1969, aos 28 anos portanto (SILVA, 2006, p. 60-61, grifos do autor).

O célere curso da vida de Gabeira (1982), apresentado na citação anterior, confere ao autor, e à literatura que emana do seu fazer laboral, um viés transgressor, combativo, que se pauta na rechaça de instrumentos que visam à homogeneização cultural, ao apagamento das diferenças identitárias, e à, consequente, escamoteação da sociedade. Nesse embate, são os lugares 
conferidos ao "contexto" e à "memória" que propiciam uma análise sistemática sobre os mecanismos de controle utilizados para se efetivar a sujeição feminina aos ditames masculinos, estes perpassados entre geraçóes, por meio da cadeia cultural misógina que impóe, ainda hoje, o estigma da preponderância do homem sobre a mulher. Com base nesse panorama tirânico, objetiva-se, com este artigo, esclarecer a importância dos conceitos de "contexto" e de "memória", dentro das relaçóes sociais, sobretudo quando estas se encontram maculadas pela violência masculina. É, pontualmente, sobre essas duas noçóes que versa a seção posterior, que se debruça sobre tais termos, no seio da Análise do Discurso, linha a qual este trabalho se perfilha.

\section{Referencial teórico: as noções de "contexto" e de "memória" à luz dos estudos linguísticos}

Os estudos sobre a concepção de "contexto" atravessam uma quantidade significativa de campos científicos que leem, a partir de suas grelhas teóricas, tal noção. Para Charaudeau (2010, p. 70), por exemplo, haveria uma bipartição contextual, por meio da qual "o contexto linguístico" designaria "a vizinhança verbal de uma determinada palavra, podendo variar em dimensão" e "o contexto discursivo" constituiria "os atos de linguagem existentes (aqueles que já foram produzidos) numa determinada sociedade e que intervêm na produção/ compreensão do texto a interpretar" (CHARAUDEAU, 2010, p. 70). Enquadrando-se na mesma grande área, mas em linha distinta, Marcuschi (2008, p. 82), na seara dos estudos de Jean-Michel Adam,

[...] argumenta sobre o posicionamento deste com relação à definição de contexto, uma vez que Adam retoma aquela noçáo de texto anterior que procedia a uma descontextualização e rejeita aquele procedimento sugerido pela citada fórmula propondo agora uma releitura que inclua o texto no contexto das práticas discursivas sem dissociar sua historicidade e suas condiçôes de produção. Nesse sentido, o contexto é algo mais do que um simples entorno e não se pode separar de forma rigorosa o texto de seu contexto discursivo [já que o] contexto é fonte de sentido (MARCUSCHI, 2008, p. 82). 
A leitura marcuschiana abarcaria, portanto, o movimento linguístico que parte do texto em direção ao contexto, este impregnado de historicidade. Nessa direção, o contexto legitimaria as trocas linguísticas interpessoais, uma vez que "os significados lexicográficos neutros das palavras da língua" assegurariam para ela "a identidade e a compreensão mútua de todos os seus falantes", sendo, portanto, o "emprego das palavras na comunicação discursiva viva sempre [...] de índole individual-contextual” (BAKHTIN, 2003, p.294). Desse modo, não haveria nenhum discurso que não remetesse a outros anteriores, nenhum enunciado que não se encontrasse encadeado a outros pretéritos, nenhum contexto que não se reportasse, de algum modo, a outras relaçóes contextuais, pois “as palavras da língua não são de ninguém, mas ao mesmo tempo nós as ouvimos apenas em determinadas enunciaçóes individuais”, mas "aí as palavras já não têm expressão apenas típica, porém expressão individual externada com maior ou menor nitidez (em função do gênero), determinada pelo contexto". (BAKHTIN, 2003, p. 293). Na esteira do olhar bakhtiniano, constatar-se-ia, portanto que

Os enunciados não são indiferentes entre si, nem se bastam cada um a si mesmo; uns conhecem os outros e se refletem mutuamente uns nos outros. Esses reflexos mútuos lhes determinam o caráter. Cada enunciado é pleno de ecos e ressonâncias de outros enunciados com os quais está ligado pela identidade da esfera da comunicação discursiva. Cada enunciado deve ser visto antes de tudo como uma resposta aos enunciados precedentes de um determinado campo (aqui concebemos a palavra "resposta" no sentido mais amplo): ela os rejeita, confirma, completa, baseia-se neles, subentende-os como conhecidos, de certo modo os leva em conta (BAKHTIN, 2003, p. 297, grifos do autor).

Observa-se, assim, que os três horizontes teóricos, arrolados até aqui, interpretam a noção de contexto, no bojo de suas teorias. Charaudeau (2010) relê tal termo na seara da Semiolinguística, Marcuschi (2008), sob a égide da Linguística Textual e Bakhtin (2003), à luz da Filosofia da Linguagem. Todos confluem, no entanto, no que diz respeito à importância do contexto nas aná- 
lises linguísticas. Contudo, é Bakhtin (2003) o teórico escolhido para nortear o que se entende, neste artigo, por contexto, dado que é, por meio do olhar do teórico russo, que se torna possível associar o traço responsivo dos enunciados aos contextos que lhes são imanentes, enlace justificável graças à memória discursiva que se mobiliza no interior dos discursos. Sobre esse termo, memória discursiva, é Brandão (2004) a estudiosa eleita como fiadora de tal conceito neste trabalho, escolha que se dá, precisamente, pela aproximação que ela viabiliza entre o contexto histórico e a memória, como se vê:

Mobiliza-se, assim, no interior da Análise do Discurso, a noção de memória discursiva. Essa noção implica o estatuto histórico do enunciado inserido nas práticas discursivas reguladas por aparelhos ideológicos do Estado. Ela se enquadra naquilo que Foucault (1971, p.11) classificou de procedimentos de controle e de delimitação do discurso: "[...] a produção do discurso é ao mesmo tempo controlada, selecionada, organizada e redistribuída por certo número de procedimentos que têm por papel conjurar dele os poderes e os perigos, de dirigir o acontecimento aleatório, de afastar dele a pesada, a irredutível materialidade". A noção de memória discursiva, portanto, separa e elege dentre os elementos constituídos numa determinada contingência histórica, aquilo que, numa outra conjuntura dada, pode emergir e ser atualizado, rejeitando o que não deve ser trazido à tona. Exercendo, dessa forma, uma função ambígua na medida em que recupera o passado e, ao mesmo tempo, o elimina com os apagamentos que opera, a memória irrompe na atualidade do acontecimento, produzindo determinados efeitos (BRANDÃO, 2004, p. 99).

Dessa forma, assim como os enunciados trazem consigo o aspecto responsivo, a memória discursiva também responde a outras memórias, produzindo "efeitos" que "tanto podem ser de lembrança, de redefinição, de transformação, quanto de esquecimento, de ruptura, de denegação do já-dito" (BRANDÁO, 2004, p. 99). Portanto, é se pensando, sobretudo, nesse efeito de lembrança, que se pretender analisar a obra de Gabeira (1982), a fim de 
se examinar a amálgama de memórias que irradia do romance e conflui, tal qual um cortejo, para a mesma direção. Destarte, é a partir da caracterização dos contextos histórico-sociais das cinco protagonistas que se alcançam as memórias discursivas de tais personagens, construtos mnemônicos capazes de revelar, apesar da passagem temporal, as mesmas ferramentas de adestramento social transmitidas ao longo dos anos, dentre as quais se destacam: a religião, a sanção moral, a dominação masculina e a morte. É acerca desses instrumentos disciplinadores que a análise alocada no próximo tópico ocupa-se.

\section{Independência ou morte: o dilema feminino em terras planetárias}

De acordo com Bourdieu (2007, p. 46), "as estruturas de dominação [...] são produtos de um trabalho incessante (e, como tal, histórico) de reprodução, para o qual contribuem agentes específicos [...] e instituiçôes, famílias, Igreja, Escola, Estado". Nesse panorama, tais aparatos dominantes asseguram que a reiteração de contextos e memórias se efetive em função de interesses escusos. Essas memórias tendem a se repetir, porque os mecanismos de regulação estancam qualquer comportamento social que se diferencie dos demais, uma vez que o autoritarismo só se fortifica naquelas relaçóes em que a homogeneização comportamental é respeitada. Daí a penalização que emana do descumprimento dessa equalização ditatorial. Sobre tais circunstâncias normativas, Gabeira (1982) retrata, com perfeccionismo discursivo, os contextos históricos e sociais, nos quais circularam mineiras que tinham, além do Estado e do gênero, outros pontos comuns, tais como a influência que lhes causava os engendramentos coercitivos instaurados na figura masculina. A presença do homem na vida de Chica da Silva é assim caracterizada por Gabeira (1982, p. 34): Chica da Silva "era escrava e logo foi violentada pelo seu dono. Como um prisioneiro nas mãos de um tirano, sempre soube que seu corpo não the pertencia e que, a qualquer momento, podia ser vendida", por isso "o que experimentou com sorte e felicidade não foi tornar-se livre, mas encontrar um dono por quem se apaixonou: o rico contratador dos diamantes da regiáo do Tejuco". Nessa passagem, constata-se que a independência feminina não era almejada por Chica, que, dentro do contexto histórico em que se encontrava, sabia da importância basilar do homem na empreitada da sobrevivência social. De forma análoga, Beja também aprendeu que, no personagem masculino, 
residia todo o eixo gravitacional da sociedade em que vivia; contudo, esse aprendizado se deu por vias ainda mais opressoras do que aquelas vivenciadas por Chica, como se observa:

O caso de Beja talvez tenha sido sentido como uma tragédia maior, porque náo tinha atrás de si a experiência de uma raça oprimida. Era branca, tinha acesso às famílias mais poderosas do arraial e, aos 15 anos de idade, foi sequestrada a mando do ouvidor português, a maior autoridade da área. Nesse momento, ela vivia só com o avô, que tentou resistir ao sequestro e foi morto a facadas. [...] O dado mais trágico era estar nas mãos do homem que, pela lei, seria o responsável pela investigação do crime (GABEIRA, 1982, p. 34-35).

Esse monopólio da violência simbólica, do qual fala Bourdieu (2007), é salientado por Pedroza (2011, p. 101) que "ressalta que é através daquele que detém o monopólio da violência simbólica legítima dentro da família que se exerce a ação psicossomática que leva à somatização da lei”, ou seja, é por meio "do trabalho de dominação, da socialização diferencial que [se] predispóe os homens a amar os jogos de poder e as mulheres a amar os homens que os jogam”. Nesse ensejo, Chica da Silva e Beja focalizam o masculino por uma ótica também masculinizada, ideia que é repassada à Olímpia e à Tiburtina, alcançando, mais adiante, Ângela Diniz. Acerca de Olímpia, Gabeira (1982) é detalhista:

Olímpia chegou a Ouro Preto no princípio do século XX. Há muitas versôes para sua loucura. [...] Mas o começo mesmo foi o seguinte: eram várias irmãs e todas bonitas. As Cota [sic]. [...] A primeira delas se casou com um homem mau que a trancava em casa e vedava portas e janelas para que ela não visse a rua. $\mathrm{O}$ pai das moças ficou tão chocado que resolveu que nunca mais deixar nenhuma de suas filhas se casarem. Olímpia era alta bonita, tinha os cabelos longos e brilhantes. Dizem que o pai guardou um baú de cartas pedindo sua mão. Um dia, ela descobriu o baú e viu: um dos pretendentes era a pessoa por 
quem fora apaixonada. Mas o rapaz já estava casado com outra, longe de Ouro Preto (GABEIRA, 1982, p. 55).

A partir de tal contexto, verifica-se o domínio masculino exercido sobre a existência de Olímpia, que não gozava de nenhum controle sobre a sua própria vida, independência rechaçada em prol do cumprimento das normas falocêntricas. Fosse à figura do pai, fosse à figura do marido, vigorava, nos contextos históricos em que viveram as cinco personagens do romance gabeiriano, a prevalência das palavras do homem, estas adotadas por Tiburtina e incorporadas ao seu jeito masculino de conduzir a própria vida:

Toda vez que se pronuncia o nome de Tiburtina, a morte e o tiroteio andam por perto. Nas caricaturas do jornal O Malho, na década de 30, ela aparecia com uma espingarda e um embornal, sertaneja pronta para emboscar quem quer que entrasse [sic] em sua área (GABEIRA, 1982, p. 68).

Tiburtina adorava o marido e ele enfrentou a opiniáo pública para viver com ela. Quando chegou a Montes Claros, vinda de Itamarandiba, era apenas uma viúva com dois filhos, dependendo da ajuda masculina para sobreviver (GABEIRA, 1982, p. 70).

O homem de Tiburtina sempre foi muito visado como líder de oposição, no dia seis de fevereiro, quando o Vice-Presidente, Melo Viana, passara, em caravana, em frente à casa da sertaneja, o homem de Tiburtina estava na porta da casa (GABEIRA, 1982, p. 71).

Nesse momento, um foguete foi lançado na direção do homem de Tiburtina que recuou meio assustado, tossiu e cuspiu sangue na palma da mão, ato retalhado por Tiburtina com a seguinte ordem: "atirem sem medo" (GABEIRA, 1982, p. 72).

Talvez, Tiburtina tenha sido a única protagonista, do quinteto gabeiriano, a desfrutar, de fato, de alguma independência física e psicológica, autonomia alcançada graças à masculinização do seu comportamento. Talvez, também por isso, ela tenha sido a única a conviver com a morte de forma tão 
próxima, preço cobrado pela busca da liberdade. Sobre a morte, testifica-se a ideia de que todas as personagens do romance faleceram sob um jugo negativo: "Agora que parecia ter transcorrido seu tempo na terra, Beja sentia muitas saudades da água de Araxá" e [...] "a filha chegou a suspeitar que estivesse louca” (GABEIRA, 1982, p. 169); Olímpia, "como todos os heróis do século XVIII que povoaram sua Ouro Preto", morreu "só e poucas pessoas foram ao seu enterro" (GABEIRA, 1982, p. 170); Chica ficou só, "assistindo lentamente ao desmoronar de seu prestígio" (GABEIRA, 1982, p. 173); Tiburtina "morreu muito louca" (GABEIRA, 1982, p. 174) e Ângela foi assassinada. Essas mortes, cada uma em um contexto histórico, parecem se reunir sob um viés pedagógico, catequizante, que reforça a punição daqueles que se desvirtuam do socialmente esperado.

Desse modo, é a partir da narrativa detalhada dos contextos subjacentes às vidas das cinco mulheres gabeirianas que o entrecruzamento de memórias se avulta e revela o rastro de dominação masculina. Nota-se que tais personagens foram obrigadas, como seres condicionados, a se verem, unicamente, pela ótica masculina, por um filtro que reforçava essa dependência. Nesse sentido, a independência implica na morte conotativa daquela mulher que, por algum motivo, afasta-se da influência masculina. Nesses casos, Beja e Tiburtina foram punidas com a morte em vida, personificada pela loucura, e Olímpia e Chica, pela tristeza da solidão e do abandono, no leito de morte. No entanto, parece ser Ângela aquela que será punida com ambas as mortes, física e figurada, aquela que será vigiada pelos quatro mecanismos regulatórios, a única que será capaz de transgredir os três primeiros, sendo, por isso, penalizada pelo quarto, cumprindo, assim, a sina de suas antepassadas. É sobre Ângela que os parágrafos posteriores se voltam.

Conforme anuncia Saffioti (1992, p. 188): “o papel das doutrinas religiosas, educativas e jurídicas, sempre foi o de afirmar o sentido do masculino e do feminino, construído no interior das relaçóes de poder" (SAFFIOTI, 1992, p. 188). Nesse caminho, é a religião e, naturalmente, "os sinos da Igreja que regem todos os movimentos do Planeta" cujo "habitante mais conhecido é Ângela Diniz", também caracterizada pelo cognome gabeiriano de "Tia Pantera” (GABEIRA, 1982, p. 36). A religião enquanto mecanismo regulatório esteve presente na vida de Ângela, desde a tenra idade, a partir da sua internação no Colégio Santa Marcelina, ideia esta corroborada no seguinte trecho: 
No colégio, o corpo a corpo começou pelos cabelos. Eram cor de mel e as irmãs resolveram que chamava a atenção, exigindo que os pintasse de preto como as outras. Tudo bem. Já a haviam despojado de sua roupa e de todos os objetos que nâo fossem regulamentares; já haviam proibido de ficar amiga de apenas uma pessoa e dedicar-se a ela; e já haviam metido em suas mãos um livro sobre a vida de Santa Maria Goretti para que mirasse em seu exemplo. E era evidente que Santa Maria Goretti não enfiava os dedinhos entre as pernas, não beijava suas amigas, nem suspirava pelos rapazes de Belo Horizonte [...] O único liberalismo era o de poder puxar a descarga sem ter de chamar ninguém para examinar o cocô, norma que não era estranha aos internatos mais rígidos (GABEIRA, 1982, p. 30- p. 31).

No excerto acima, Fernando Gabeira (1982) denuncia o apagamento de diferenças, as práticas abusivas sofridas por Ângela e por suas colegas de internato, dentro das instituições religiosas. Contudo, como ressaltado no início desta subseção, Ângela é dotada da capacidade de subverter normas autoritárias e o faz desde a infância:

Felizmente as internas sabiam se proteger com as armas que os colonizados sofisticaram ao máximo: usar a própria couraça religiosa montada sobre elas. Eram forçadas a assistir à missa todas as manhấs em jejum e aprenderam a desmaiar quando queriam um pouco de paz ou mesmo tomar o café mais cedo. Aprenderam a fazer penitência com as mãos estendidas na capela, passando através delas, para as alunas do externato, os bilhetes de amor que as mantinham animadas durante toda a semana. Aprenderam a se mexer sobre os lençóis sem despertar suspeitas nas freiras que cercavam os quatro cantos do dormitório, atentas ao mínimo suspiro, ranger de camas ou grito noturno (GABEIRA, 1982, p. 32).

Essa postura transgressora se confirma no enfrentamento de "Tia Pantera" às sanções sociais, estas baseadas em uma 
educação elementar [que] tende a inculcar maneiras de postar todo o corpo, ou tal ou qual de suas partes (a mão direita, masculina, ou a mão esquerda, feminina), a maneira de andar, de erguer a cabeça ou os olhos, de olhar de frente, nos olhos, ou, pelo contrário, abaixá-los para os pés etc., maneiras que estáo prenhes de uma ética, de uma política e de uma cosmologia (...) (BOURDIEU, 2007, p. 38).

Nesse caminho, ainda segundo Bourdieu (2007, p. 49), o efeito da dominação simbólica (seja ela de etnia, de gênero, de cultura, de língua etc.) "se exerce não na lógica pura das consciências cognoscentes, mas através dos esquemas de percepção, de avaliação e de ação”. Assim, o bom aprendizado social, nos parâmetros da tradicional família mineira dos anos cinquenta, segundo Gabeira (1982, p. 30), perpassava a arte de se "aprender a comer laranja com garfo e faca", tarefa ensinada nos colégios que não hesitavam "um segundo sobre o sentimento daquela educação: os melhores casamentos saíram dali, daquela fornalha de virtuosas donas-de-casa, treinadas para obedecer e sistematicamente afastadas de qualquer conhecimento" que pudesse "perturbar sua evolução" (GABEIRA, 1982, p. 31). Essa produção em série de mulheres casadoiras parecia náo agradar à Ângela, que perturbava a ordem vigente:

No dia do casamento de sua irmã, por exemplo. Lá está o álbum de família, onde ela aparece com uma minissaia de paetê negro e uma touca, as pernas de fora, um sorriso travesso, os olhos arregalados. Era fácil pressentir o escândalo na igreja em que estavam todas vestidas até o tornozelo, os homens de terno escuro, fuzilando com uma expressáo severa aquele ser interplanetário, com as pernas bem plantadas, o ar de deboche e, o que é pior, cintilando sob o reflexo das luzes, no altar de Cristo, Nossa Senhora e os tristes santos de nossa constelaçáo religiosa (GABEIRA, 1982, p. 87).

Como visto, Ângela Diniz desobedecia às normas religiosas, violava as sançóes sociais, tudo em prol de uma vida real, sem hipocrisias ou engodos comportamentais. Essas noçóes são passíveis de serem retomadas graças ao 
trabalho historiográfico e jornalístico de Gabeira (1982), que recria os contextos pelos quais a "Pantera" circulou, propiciando ao leitor que figurativize as memórias de Ângela por meio de um telão imagético, que se projeta na mente daqueles que se servem do texto gabeiriano. Entretanto, como adiantado neste artigo, o descumprimento de todos os artefatos regulatórios, somatizados na ação do desquite, desdobrou-se em uma retaliação social constante, comprovada no falar de Gabeira (1982, p. 75): “Tia Pantera”, depois da separação, "vivia sob um fogo cruzado. De um ponto bem preciso, conhecido como moral, tradiçáo, ou o diabo que fosse, bombardeavam seu comportamento de mãe e ameaçavam com a perda de seus filhos”. Essa represália social ganhou força maior e Diniz teve que se "defrontar com uma justiça essencialmente masculina, sempre pronta a condenar a mulher que escapasse aos padróes idealizados pelos homens" (GABEIRA, 1982, p. 76). Quiçá, condenada pela memória discursiva de suas antepassadas, Ângela tenha duvidado "da própria capacidade de sobreviver emocionalmente sozinha” e, por isso, tenha se refugiado na companhia de Doca Street, aquele que seria o seu futuro algoz (GABEIRA, 1982, p. 79). Entretanto, a questão que se formula repousa sobre descompasso entre o vanguardismo/transgressividade de Diniz e a sua posterior docilidade, diante de Doca. Esse paradoxo, provavelmente, nunca será solucionado, no entanto Bourdieu (2007) lança mão de algumas noçóes, que, se não esclarecem definitivamente tal impasse, pelo menos permitem uma reflexão sobre tais circunstâncias:

A dominação masculina, que constitui as mulheres como objetos simbólicos, cujo ser (esse) é um ser-percebido (percipi), tem por efeito colocá-las em permanente estado de insegurança corporal, ou melhor, de dependência simbólica: elas existem primeiro pelo, e para, o olhar dos outros, ou seja, enquanto objetos receptivos, atraentes, disponíveis. Delas se espera que sejam "femininas", isto é, sorridentes, simpáticas, atenciosas, submissas, discretas, contidas ou até mesmo apagadas. E a pretensa "feminilidade" muitas vezes não é mais que uma forma de aquiescência em relação às expectativas masculinas, reais ou supostas, principalmente em termos de engrandecimento do ego. Em conseqüência, a dependência em relação aos outros 
(e não só aos homens) tende a se tornar constitutiva de seu ser. (BOURDIEU, 2007, p. 82).

Dessa maneira, "o homem [Doca Street] usava seu poder de macho sem nenhuma base econômica, pois era praticamente sustentado por ela. Só os fantasmas culturais que habitavam a um e outro garantiam a sobrevivência do domínio", fantasmas estes que habitavam o recôndito das memórias discursivas, estas povoadas por mecanismos regulatórios inquestionáveis (GABEIRA, 1982, p. 185). Nesse sentido, é a cogitação, por parte de Diniz, de uma possível separação entre ela e o marido que culmina na tragédia pessoal de Ângela. Nesse contexto, é por meio da separação, ato máximo de independência, que rompe os três mecanismos inventariados neste artigo sanção moral, a religião e a dominação masculina -, que a morte se revela, com toda sua força coercitiva.

\section{Fernando Gabeira e sua literatura-estandarte}

Nos dizeres de Sartre (1993, p. 61-62):

Um escritor é engajado quando trata de tomar a mais lúcida e integral consciência de ter embarcado, isto é, quando faz o engajamento passar, para si e para os outros, da espontaneidade imediata ao plano refletido. O escritor é mediador por excelência, e o seu engajamento é a mediação. Mas, se é verdade que se deve pedir contas à sua obra a partir da sua condição, é preciso lembrar ainda que a sua condição não é apenas a de um homem em geral, mas também, precisamente, a de um escritor (SARTRE,1993, p. 61-62).

Face ao exposto na citação sartriana, vislumbra-se, na produção textual de Gabeira (1982), um tom militante que denota todo o engajamento do escritor frente aos problemas sociais brasileiros. Em uma sociedade globalizada e, essencialmente, capitalista, Gabeira (1982) prefere mostrar a própria face no enfrentamento de questóes delicadas, como aquelas ligadas ao abuso de poder. Essa tônica de resistência e do combate a um sistema, que impera por 
meio de modelos macroeconômicos totalitários, e produz o apagamento de diferenças culturais, encontra-se na literatura, em língua portuguesa, produzida por Gabeira (1982), que parece ser um bálsamo, um consolo, àqueles que buscam uma leitura crível e comprometida com o social. Essas características se revelam, nas linhas gabeirianas, mormente, no que tange à luta por uma democracia, de fato, igualitária. Com esse objetivo, Gabeira (1982) volta ao ano de 1975 e achaca, de forma irônica e plausível, todos aqueles que transformaram o julgamento da morte de Ângela Diniz em um circo, em uma arena de egos, na qual a promotoria pôde exercer todo o seu dom artístico, como se vê: "o primeiro julgamento do homem que matou Tia Pantera foi um espetáculo na televisão", [...] "o promotor levantava dramaticamente a pistola do crime e grupos de mulheres da região, comovidas com o retrato do homem, improvisavam um coro a seu favor" (GABEIRA, 1982, p. 179).

Por meio da análise desse julgamento, Gabeira (1982) traz à tona a corrupção e os interesses particulares envolvidos em uma querela de dimensóes nacionais:

Nesse júri, a grande vedete foi o velho advogado, esse da Vênus Lasciva destilando veneno do instinto sexual e tudo mais. Considerado um grande criminalista, tinha sido ministro, impondo um grande respeito aos juízes e adversários. Além do mais, decidiu que aquele seria seu último júri. Queria fazê-lo maravilhosamente, para encerrar sua carreira histórica (GABEIRA, 1982, p. 179).

A busca pelo estrelato e por uma causa que valesse a sua aposentadoria fez com que o advogado de defesa voltasse os seus argumentos contra a face de Ângela Diniz, que, batizada de "Vênus Lasciva", teve a sua imagem arranhada, em nome da defesa da honra de seu marido, como se constata neste excerto:

[O advogado] Apresentaria uma defesa mostrando como Tia Pantera buscava a morte e escolheu um homem preciso para realizá-la. Mostraria mais, porque não era apenas um advogado, mas um pensador, que Tia Pantera morreu ao desprezar todos os valores morais da sociedade. A solenidade do locutor 
de televisão cuidaria de indiretamente de ecoar essa mensagem para todo o país: quem despreza os nossos valores morais acaba morrendo no seu próprio impulso autodestrutivo. A questão de quem vai consumar a morte, a pessoa que vai realizar o desígnio subconsciente da vítima, era secundária (GABEIRA, 1982, p. 180).

Além disso, como bem retrataria Gabeira (1982), o defensor do "homem", modo como o autor nomeia Doca Street - dada a importância do seu gênero, no contexto jurídico e social -, valeu-se de mecanismos patêmicos, de clichês, de lugares-comuns e de outros artifícios, matematicamente pensados, a fim de sensibilizar o júri e de livrar o seu cliente. Para tanto, adotou os seguintes argumentos:

Ele: dinâmico executivo de 42 anos, apaixonado por sua mulher, relativamente brilhante nos negócios financeiros, neto de um industrial progressista, perde a cabeça quando entra na sua vida aquela da qual só poderia se livrar com a morte.

Ela: prostituta escarlate, havia abandonado os filhos, os valores da sociedade e procurava inconscientemente a morte; ao encontrá-lo, começa por seduzi-lo, passando a provocá-lo até que executa o ato que ela tanto buscava (GABEIRA, 1982, p, 181).

Argumentação combatida por Gabeira (1982), que, baseando-se no princípio da isonomia, expóe os argumentos da acusação:

Ele: ex-salva-vidas de grã-finas em Miami aplicou um golpe do baú em São Paulo casando-se com uma milionária; apaixonou-se por Tia Pantera e começou a explorá-la também, convencendo-a progressivamente a botarem o dinheiro numa conta conjunta.

Ela: seu maior sonho era juntar-se aos filhos de Minas; resistia ao assédio até que ele lançou mão do argumento final: a pistola Beretta (GABEIRA, 1982, p, 181). 
Apesar do esforço de Gabeira (1982), a realidade é mantida na sua ficção, e o desfecho do julgamento acaba por se resumir na frase: "o velho advogado conseguiu livrar o homem da cadeia e realizou seu grande sonho de despedida" (GABEIRA, 1982, p, 181). Entretanto, tal perda jurídica não é focalizada, pelo autor, somente pelo viés negativo. Pelo contrário, o desfecho do julgamento gera o desejo de justiça, a busca pelos ideais de "ordem e progresso”. Nessa direção, Gabeira (1982, p. 182) descreve os primeiros sinais de mudança inaugurados no cenário político-social brasileiro: a "ditadura militar que se instalara no país logo depois do casamento de Tia Pantera começara a decair ligeiramente". Com a decadência, foi necessária "uma abertura política, [...] ecologia, negros, mulheres, homossexuais eram temas que começavam a aparecer para o grande público" (GABEIRA, 1982, p. 182). Mais adiante, Gabeira (1982), fala sobre as mudanças no panorama social e sobre o descortiçamento de minorias engajadas:

Um dia, os muros brancos das principais cidades amanheceram com uma inscrição: quem ama, não mata. Os emergentes grupos feministas decidiram denunciar a onda de crimes contra mulheres e tomaram o caso de Tia Pantera como um exemplo de violência machista. [...] As notícias já não saíam apenas nas páginas policiais, mas eram tópicos da reflexão política. Novos tempos, tempos novos (GABEIRA, 1982, p. 182-183).

Imbuído desse espírito de renovação e esperança, Gabeira (1982) finaliza seu livro, obra que nasce de histórias violentas, e que, por causa dessas violências, projeta-se como fonte de memória discursiva, de testemunhos históricos, que existem, no seu romance, precisamente, para não permitir que situações pretéritas, dotadas de tamanha impunidade, repitam-se, agora e no futuro. Assim, tomando-se, novamente, as palavras de Sartre (1993, p. 21), como fios condutores, defende-se, aqui, um fazer literário no qual "o mundo e especialmente o homem para os outros homens [..] assumam em face do objeto, assim posto a nu, a sua inteira responsabilidade". Do mesmo modo, "a função do escritor é fazer com que ninguém possa ignorar o mundo e considerar-se inocente dele" (SARTRE, 1993, p. 21), inocência com a qual, felizmente, Gabeira (1982) não compactua, o que permite que as suas obras sejam 
verdadeiras literaturas-estandartes, romances que carregam consigo as bandeiras do enfrentamento e da resistência, diante do autoritarismo social vigente, ainda, na hodiernidade.

\section{Referências}

BAKHTIN, Mikhail. Estética da Criação Verbal. 4.ed.São Paulo: Martins Fontes, 2003.

BOURDIEU, Pierre. A Dominação Masculina. 5. ed. Rio de Janeiro: Bertrand Brasil, 2007.

BRANDÃO, Helena Hathsue Nagamine. Introdução à análise do discurso. 2.ed. Campinas: Editora da Unicamp, 2004.

CHARAUDEAU, Patrick. Linguagem e discurso: modos de organização. 2.ed. São Paulo: Contexto, 2010.

GABEIRA, Fernando. Sinais de Vida no Planeta Minas. Rio de Janeiro: Nova Fronteira, 1982.

MARCUSCHI, Luiz Antônio. Produção textual, análise de gêneros e compreensão. São Paulo: Parábola Editorial, 2008.

PEDROZA, Maria Luiza. A dominação masculina. Espaço do Currículo, 4:100-102, João Pessoa, 2011.

SAFFIOTI, Heleieth Iara Bongiovani. Rearticulando gênero e classe social. In: COSTA, Albertina de Oliveira, BRUSCHINI, Cristina. (orgs.) Uma questão de gênero. Rio de Janeiro: Rosa dos Tempos, 1992.

SARTRE, Jean-Paul. Que é a literatura? São Paulo: Ática, 1993.

SILVA, Mário Augusto Medeiros da. Prelúdios e Noturnos: ficçôes, revisões e trajetórias de um projeto político. 2006. 280f. Dissertação (Mestrado em Sociologia) - Instituto de Filosofia e Ciências Humanas, Universidade Estadual de Campinas, Campinas, 2006. 
WOMEN'S VIA CRUCIS ON THE PLANET MINAS: RESISTANCE AND CONFRONTATION IN FERNANDO GABEIRAS LITERATURE

\begin{abstract}
This article has as its object of study the book Sinais de Vida no Planeta Minas, written by Fernando Gabeira, work that stands out for committed literature and the antagonism to the mechanisms of social sleight. In this opportunity, the present text relies on a bibliographic referential anchored on Discourse Analysis, favorable line to provide theoretical subsidies for the examination of the selected corpus.
\end{abstract}

KEYWORDS: discourse; discursive memory; context.

Recebido em: 18/10/2014 Aprovado em: 25/02/2015 